\title{
OPTIMIZATION OF TITANIUM PERFORMANCE IN HIGH CARBON SILICON KILLED STEELS, INJECTED IN VACUUM DEGASSER THROUGH A HIGHLY COMPACTED FERROTITANIUM WIRE*
}

\author{
Luis Gonzalo Arqueros Villa ${ }^{1}$ \\ Rodrigo Espinoza ${ }^{1}$ \\ Fernando Velázquez Guzmán ${ }^{2}$
}

\begin{abstract}
Titanium is an alloying element used to refine grain size in steel and improve its physical and mechanical properties. In some stainless steels it is used to increase the resistance to corrosion by the precipitation of titanium carbides or carbonitrides. Its alloying performance is highly variable and depends largely on the stage of the secondary metallurgy process when it is added. Furthermore, the addition method (wire injection or direct addition) has a remarkable influence in secondary refining. This paper describes the tests performed in vacuum degasser (VD), with a highly compacted and encapsulated Ferrotitanium wire (FeTi HC). The yield of titanium in steel increased from $52 \%$ to $89 \%$. Moreover, the consumption of the highly compacted Ferrotitanium was optimized.
\end{abstract}

Keywords: Ferrotitanium highly compacted, degasser, titanium carbides, high carbon steel.

Compañía Siderurgica de Huachipato, CAP.

Injection Alloys México S.A. de C.V. 


\section{INTRODUCTION}

Several methods are employed to add titanium to liquid steel, being one of the most important the injection of Ferrotitanium powder highly compacted and encapsulated in wire. Due to the high reactivity of titanium with some elements such as oxygen, carbon, nitrogen and sulfur, its performance is highly variable and dependent of the moment of addition during the refining process. This behavior may lead in some cases to desirable properties, but in others, it may reduce the yield [1]. At $1600{ }^{\circ} \mathrm{C}$ titanium has a great affinity for oxygen, which is why it is used sometimes as a powerful deoxidizer in steel. However, this practice can be very expensive for the steelmaker so it is preferred to use aluminum for de-oxidation purposes. Once the liquid steel has been completely de-oxidized, the performance of titanium should be maximized. The main influence of titanium on steel quality is associated with the formation of carbides, nitrides and carbonitrides [2]. These intermetallic compounds precipitate at the austenitic grain boundaries and prevent their growth during subsequent heat treatments. The most common titanium alloy for powder injection purposes is the Ferrotitanium eutectic $(68-70 \% \mathrm{Ti})$ which has the lowest melting point $\left(1085^{\circ} \mathrm{C}\right)$ as presented in the equilibrium diagram shown in Figure 1.

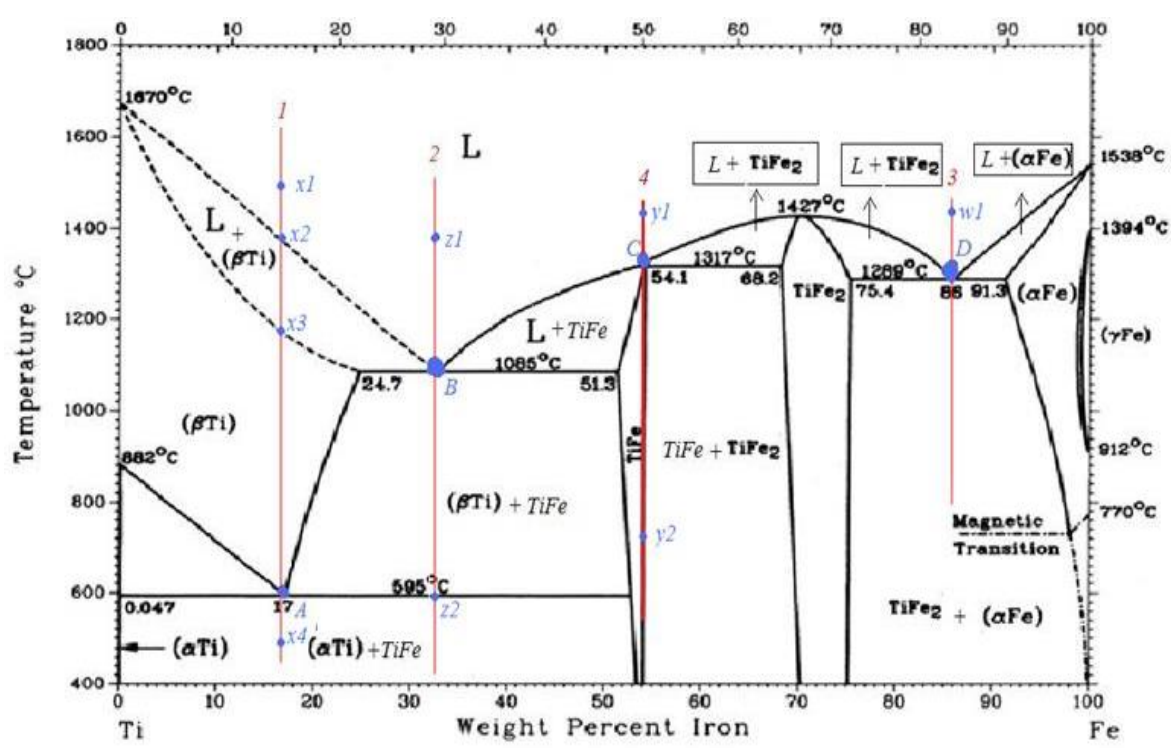

Figure 1. Fe-Ti equilibrium diagram [1]

Due to its higher density and lower melting temperature, Ferrotitanium is dissolved faster in the liquid steel, obtaining better recoveries in most of the cases.

The wire injection technology was developed in the 1980s (Conventional Cored Wire, CCW) aiming to optimize the penetration of Ferrotitanium into liquid metal, which would prevent oxidation losses [3]. However, this technology may bring some disadvantages, e.g. unstable performance. This problem may be related to an inadequate wire filling generated by a low powder compaction. Also a lack of penetration produced due to an improper injection speed may have an important effect in the yield unsteadiness.

This paper describes a project developed at Huachipato Siderurgical Company (CAP, Chile) aiming to improve the titanium yield by using a highly compacted and encapsulated Ferrotitanium wire with a thicker wall thickness. This technology allowed a higher penetration into the liquid steel aided by a higher compaction of 
Ferrotitanium powder. In this way it was possible to obtain a maximum dissolution in the bottom of the ladle giving as result an increment in the titanium yield. The tests were performed in a vacuum degasser where the de-oxidation of the liquid steel is guaranteed.

\section{BACKGROUND}

Huachipato Steel Company is an integrated steelworks that produces billets and bars made of carbon steel and alloy steels for the construction industry. It is located in the community of Talcahuano near the city of Concepción, Chile. Its steel making route is: Basic oxygen furnace (BOF) - Ladle Furnace (LF) - Vacuum degasser (VD) Continuous casting of billets or bars (CC), see Figure 2. The average weight of the heats is 105 ton.

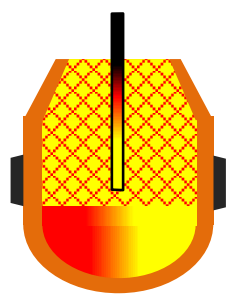

BOF

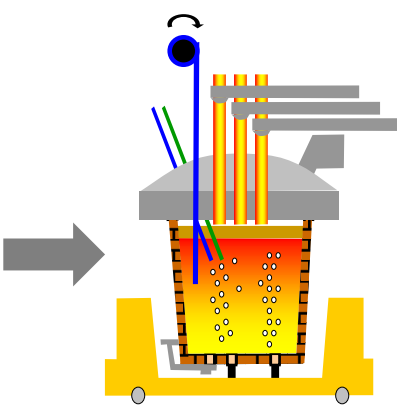

$\mathbf{L F}$

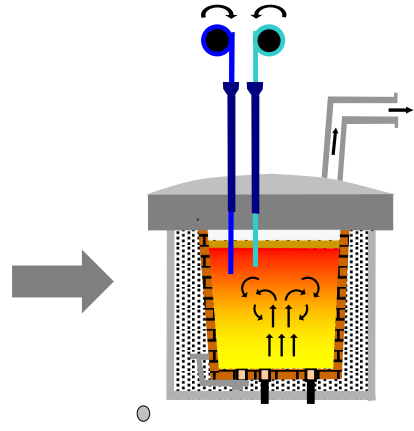

VD

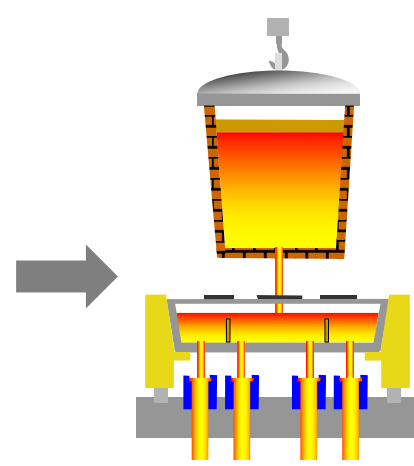

$\mathrm{CC}$

Figure 2. Steelmaking route at Compañía Siderúrgica de Huachipato, CAP Chile.

\subsection{Ferrotitanium conventional (FeTi CCW).}

In CAP Steel, some high carbon steels for applications in the mining industry are injected with FeTi wire. The role of titanium in these kind of steels is very important to achieve the toughness and wear resistance requirements.

The normal FeTi treatment is carried out with conventional cored wire. In this presentation, FeTi powder is encapsulated in a steel sheath which is lately closed by drawing process. This process generates a fold that is 4 times the thickness of the sheath which serves for preventing the ferroalloy escaping from the wire [4]. Figure 3 shows the cross-section of a conventional wire.

The filling rate of the wire used is $370 \mathrm{~g} / \mathrm{m}$ (eutectic of $68-70 \% \mathrm{Ti}$ ) with a diameter of $13 \mathrm{~mm}$ and a wall thickness of 0.4 to $0.6 \mathrm{~mm}$. 


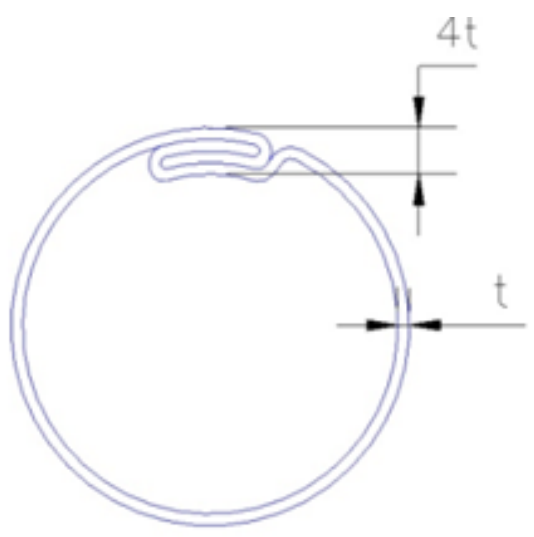

Figure 3. Cross-sectional schematic of FeTi CCW.

The FeTi CCW injection process was performed in the VD tank after the high vacuum treatment of the steel. The injection speed was set at $120 \mathrm{~m} / \mathrm{min}$. The yield of titanium obtained for the 874 heats under study was $52 \%$ average with a standard deviation of $12.9 \%$. Depending on the steel grade, the Ti\% objective ranged from 0.008 to 0.026 . For steels with higher Ti\% requirement, FeTi CCW consumption increased, but the yield was lowered. In Figure 4 can be observed that $97 \%$ of the heats analyzed had $\mathrm{Ti}$ targets higher than $0.020 \%$, obtaining yields under $55 \%$ and consumption rates greater than $0.20 \mathrm{~kg} \mathrm{Ti} /$ ton.

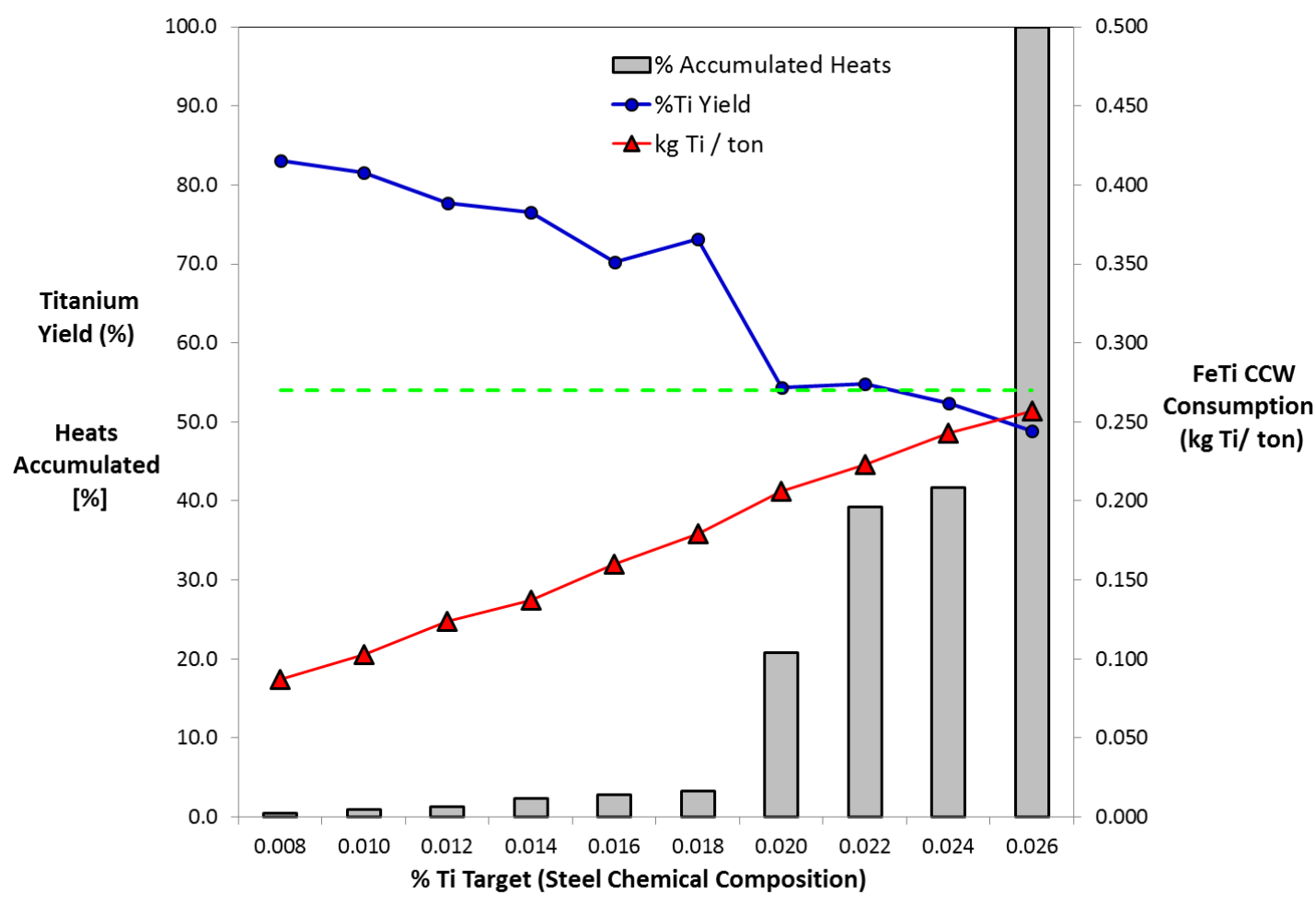

Figure 4. Ti yield reduction and consumption vs. \%Ti target.

In general terms, these low Ti yields with the FeTi CCW are associated with its lower wall thickness and its higher injection rate in liquid steel. Sarbendu et al. [5] developed a mathematical model to estimate the melting time of conventional wire 
steel sheet and to evaluate its impact on the yield of the injected ferroalloy. According to these estimations, if the FeTi CCW is injected at $120 \mathrm{~m} / \mathrm{min}(2 \mathrm{~m} / \mathrm{s})$ the maximum depth reached by the wire into the liquid bath will be $2.4 \mathrm{~m}$ (Figure 5). This is due to the fact that for higher injection rates, the wall thickness of the first layer of solidified steel, produced by the effect of the super-cooling around the sheet, will have a lower wall thickness thus reducing the melting time of the wire and then reaching fewer depths (Figure 6). On the other hand, if the wire is injected at low speed, this first skin or shell will grow while slowing the melting of the wire, allowing to reach greater depths in the liquid bath. For 105 ton heats, the steel column height is $3.1 \mathrm{~m}$, releasing the FeTi powder at $0.7 \mathrm{~m}$ from the bottom of the ladle. This may lead to Titanium leftover since the FeTi powder that does is not dissolved in the steel reacts with the slag.

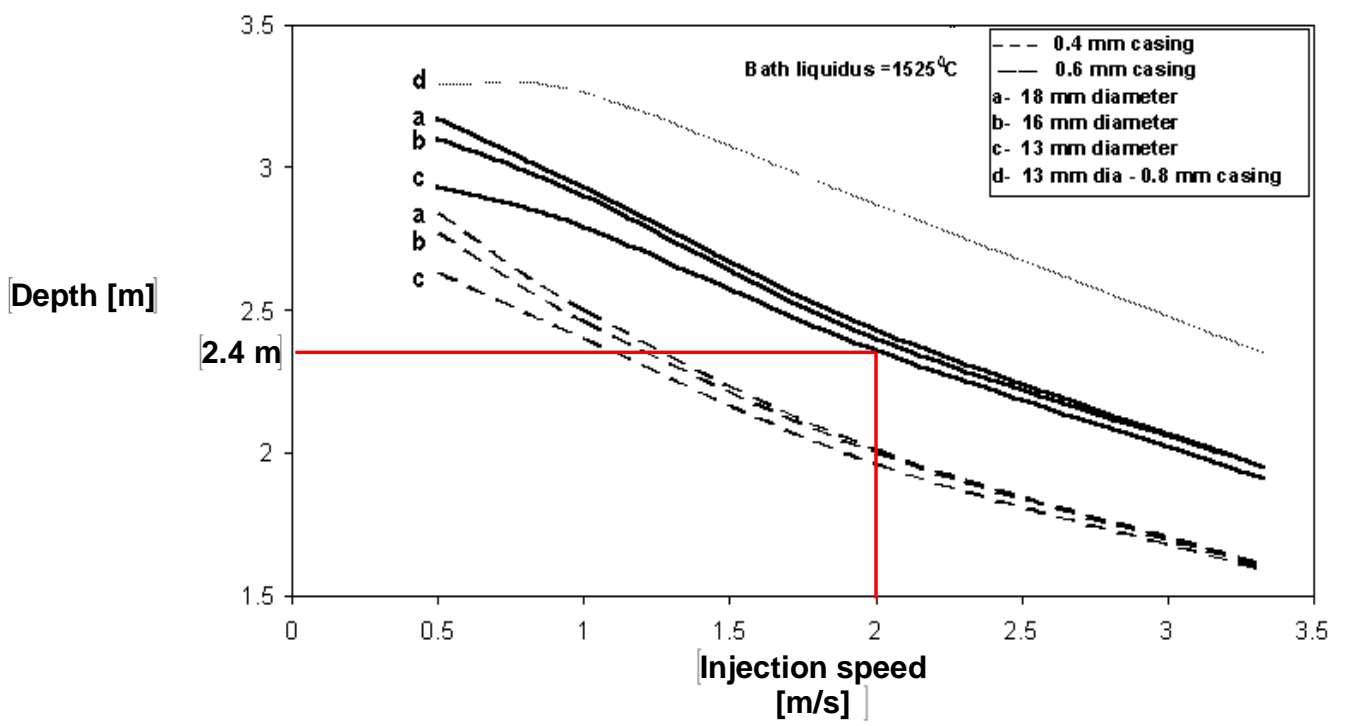

Figure 5. Maximum depth reached by FeTi CCW at $120 \mathrm{~m} / \mathrm{min}(2 \mathrm{~m} / \mathrm{s})$.

Some efforts were made to improve the performance of Titanium; however, tests with different speeds induced mechanical drawbacks such as wire breaks. These problems, not only cause delays in the process, but also increase the risk of heats out of chemical specification. Figure 6 shows a normal distribution of the Titanium yields obtained in the 874 heats analyzed according to the final $\mathrm{Ti}$ content in the steel. It can be observed that $5 \%$ of the heats analyzed had less than $0.0080 \% \mathrm{Ti}$, i.e. they were out of specification and their average yield was $34 \%$. Furthermore $92 \%$ of the analyzed heats were within the chemical specification (between $0.008 \%$ $0.018 \% \mathrm{Ti}$ ). For such heats the $\mathrm{Ti}$ yield observed ranged from $39 \%$ to $67 \%$. Moreover, only $3 \%$ of the treated heats had yields greater than $76 \%$, with $\mathrm{Ti}$ content above $0.018 \%$.

Considering these low yields, arose the need of finding a FeTi wire alternative with a higher wall thickness that could increase the titanium yield aided by a better dissolution of the powder at the bottom of the ladle. 


\section{DEVELOPMENT}

\subsection{Highly Compacted Ferrotitanium (FeTi HC).}

In order to delay the wire melting, a new $\mathrm{FeTi}$ wire $(68-70 \% \mathrm{Ti})$ with a higher wall thickness $(1.2 \mathrm{~mm})$ was developed. Such wire has a diameter of $14 \mathrm{~mm}$ and also increased mechanical properties. The improvement in the strength of the steel sheath allows an injection with more rigidity which favors higher depth penetration even at lower injection speeds. Additionally, the risk of wire breaks is highly reduced compared against FeTi CCW.

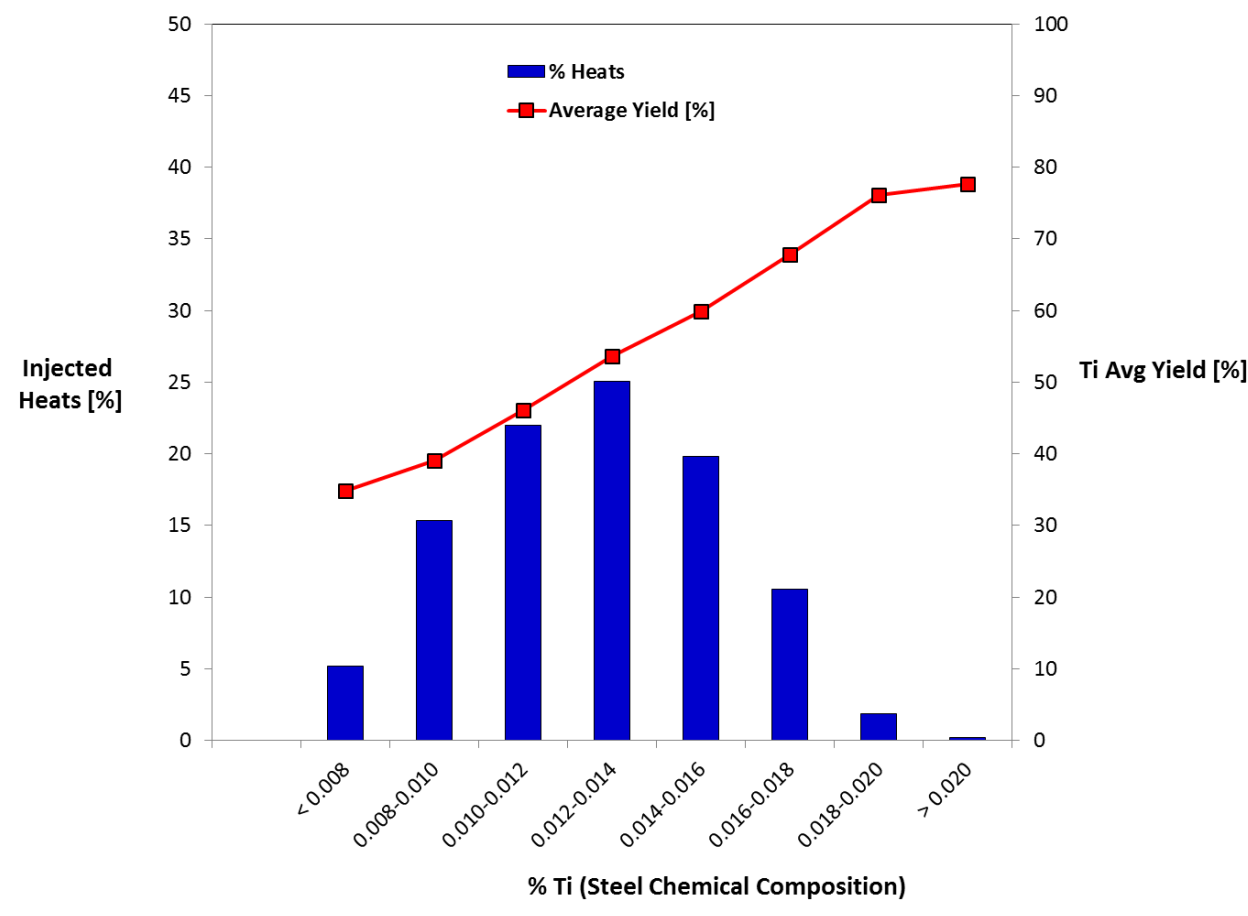

Figure 6. Normal distribution of average yield (FeTi CCW).

Another of the most outstanding features of this new wire generation is the sealing of the steel sheath, which is done with high frequency (HF) welding process. This welded seal eliminates the traditional "hook" of closure characteristic of the conventional wires, promoting an improved protection against the oxidation and degradation of the ferroalloy. In this way, a better quality of the powder at the injection time is obtained.

Finally, high compaction of the FeTi powder (98\%) enables to obtain a homogeneous filling of $410 \mathrm{~g} / \mathrm{m}$ throughout the wire coil. This high compaction have a quite important positive impact in the repeatability of Ti\% supplied and therefore a low standard deviation in wire performance. Figure 7 shows a cross-sectional schematic of the highly compacted FeTi wire. 


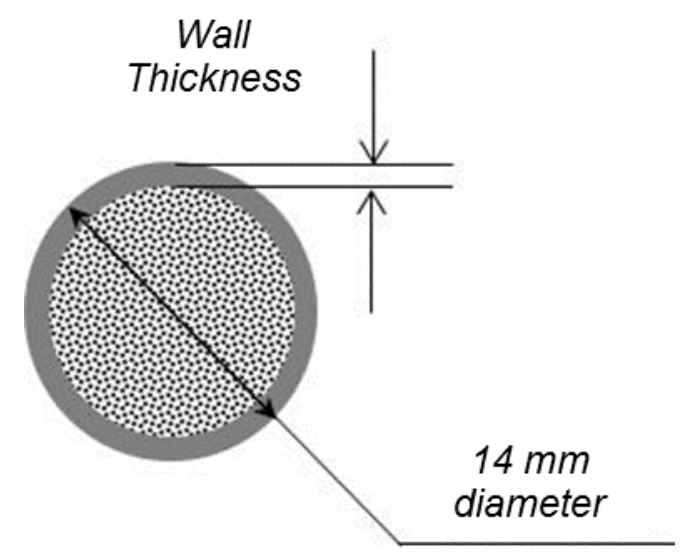

Figure 7. Cross-sectional schematic of the highly compacted FeTi wire.

\section{INDUSTRIAL TESTING IN VACUUM DEGASSER}

\subsection{First Stage}

This work with FeTi-HC comprehended, at the first stage, 13 heats of high $\mathrm{C}$ steel with a chemical specification of $0.9 \% \mathrm{C}$ and 0.0080 to $0.0180 \% \mathrm{Ti}$. The injection tests were carried out in Vacuum Degasser Tank \# 1 (VD \#1). The average weight of treated heat was 105.7 ton of steel. In order to define a first approximation of the rate of injection of FeTi HC, the model proposed by Sarbendu [5] was considered. The temperature of the liquid steel in these high $\mathrm{C}$ steels just before injecting FeTi HC ranged from 1500 to $1510^{\circ} \mathrm{C}$. According to these conditions of lower temperature, a time for the fusion of the sheath of $2 \mathrm{~s}$ was assumed. The injected speed was set at $1.5 \mathrm{~m} / \mathrm{s}(90 \mathrm{~m} / \mathrm{min})$ to reach the bottom of the ladle. This injection speed was proposed for the beginning of the tests and according to the results obtained the necessary adjustments in speed would be made.

Figure 8 shows the evolution of the yield and consumption of Titanium in steel with $\mathrm{FeTi} \mathrm{HC}$ in the 13 heats treated. It is observed a slight increment of the Ti yield as the tests progressed. Moreover, the current \% $\mathrm{Ti}$ was always higher than the objective. Such excellent stability allowed to reduce the length of FeTi HC wire injected ensuring the compliance of chemical composition. Table 1 presents the results obtained in this first stage with FeTi HC in VD \#1. The length of FeTi HC injected was reduced from $65 \mathrm{~m}$ to $43 \mathrm{~m}$ and the average yield was $92 \%$.

\subsection{Second Stage}

The second stage of this project covered 262 heats, $95 \%$ of these were treated in the VD and the remaining $5 \%$ in the LF. In this second phase, a reference yield value of $90 \%$ was considered to calculate the meters of wire to be injected according to the $\% \mathrm{Ti}$ desired. The injection rate was set the same $90 \mathrm{~m} / \mathrm{min}$. Table 2 shows the $\mathrm{Ti}$ yield results obtained at each treatment station. Although the average yield was lower than for stage I, the results were within the same scatter band and highly above the yields obtained with FeTi CCW. Furthermore, the average wire consumption in this second phase were lower (17.1 and $17.8 \mathrm{~kg}$ per heat) compared 
with those obtained for the first 13 heats $(22.4 \mathrm{~kg})$. Figure 9 shows the average yields of Titanium with the FeTi $\mathrm{HC}$ wire obtained at each treatment station.

Figure 10 shows the distribution of the yields obtained in each VD tank, as well as in the LF station. It is observed that the best yields were obtained in heats treated in VD \#1 where $76 \%$ of the heats treated showed yields above $80 \%$, while for VD \#2 and LF, 68 and $58 \%$ of the heats surpassed such yield value respectively.

In general terms better yield results are obtained in VD stations. This is an effect of the better de-oxidation conditions of the steel prior to the injection of FeTi $\mathrm{HC}$ compared against LF. On the other hand, another factor that may have influenced this lower Ti yield in LF is the type of treated steel.

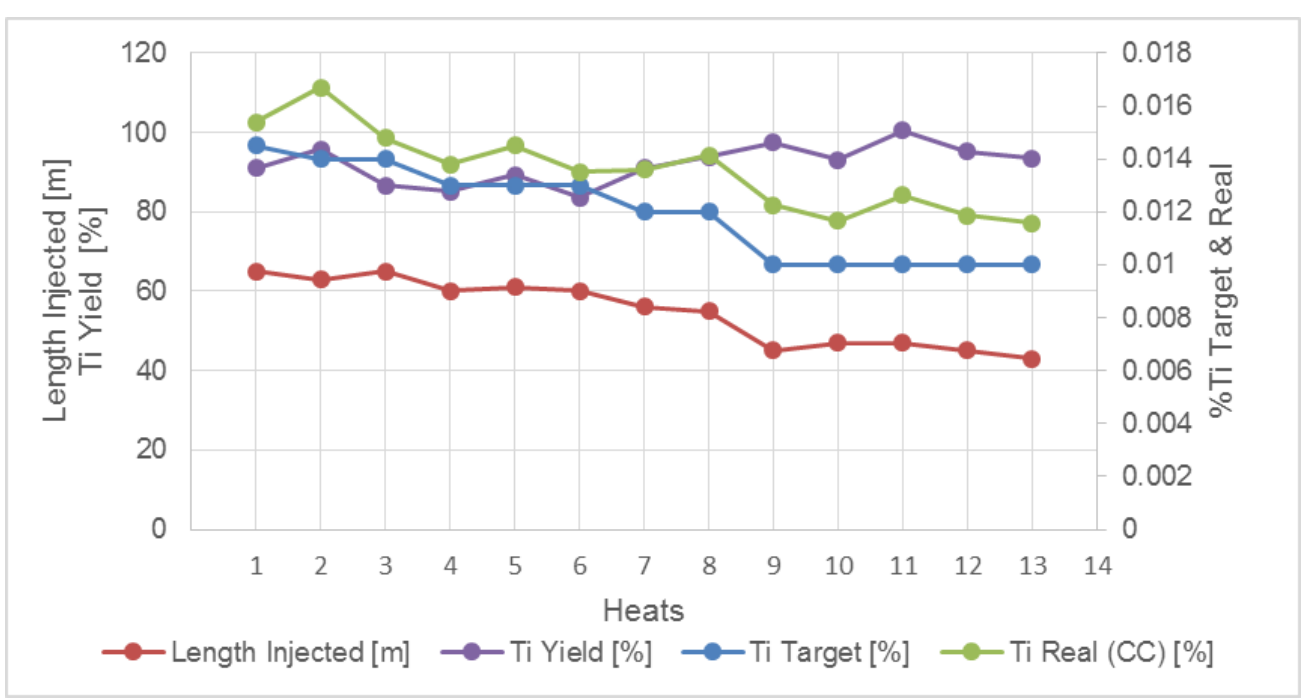

Figure 8. Ti yield \& consumption evolution during first stage.

Table 1. First stage results in VD \#1

\begin{tabular}{ccccccccc}
\hline Heat & $\begin{array}{c}\text { Steel } \\
\text { Grade }\end{array}$ & $\begin{array}{c}\text { Liquid } \\
\text { Steel } \\
\text { [ton] }\end{array}$ & $\begin{array}{c}\text { \% Ti } \\
\text { Target }\end{array}$ & $\begin{array}{c}\text { FeTi }-\mathbf{H C} \\
\text { Length } \\
\text { Injected }[\mathrm{m}]\end{array}$ & $\begin{array}{c}\text { FeTi }-\mathbf{H C} \\
{[\mathbf{k g}]}\end{array}$ & $\begin{array}{c}\mathrm{Ti} \\
{[\mathbf{k g}]}\end{array}$ & \% Ti Real & $\begin{array}{c}\% \mathbf{T i} \\
\text { Yield }\end{array}$ \\
\hline 1 & $\mathrm{C}$ & 110.0 & 0.0145 & 65 & 26.6 & 18.6 & 0.0154 & 91.0 \\
\hline 2 & $\mathrm{C}$ & 103.5 & 0.0140 & 63 & 25.8 & 18.0 & 0.0167 & 95.8 \\
\hline 3 & $\mathrm{C}$ & 109.0 & 0.0140 & 65 & 26.6 & 18.6 & 0.0148 & 86.7 \\
\hline 4 & $\mathrm{C}$ & 106.0 & 0.0130 & 60 & 24.5 & 17.2 & 0.0138 & 85.2 \\
\hline 5 & $\mathrm{C}$ & 107.5 & 0.0130 & 61 & 24.9 & 17.5 & 0.0145 & 89.3 \\
\hline 6 & $\mathrm{C}$ & 106.5 & 0.0130 & 60 & 24.5 & 17.2 & 0.0135 & 83.7 \\
\hline 7 & $\mathrm{E}$ & 107.3 & 0.0120 & 56 & 22.9 & 16.0 & 0.0136 & 91.0 \\
\hline 8 & $\mathrm{E}$ & 104.5 & 0.0120 & 55 & 22.5 & 15.7 & 0.0142 & 93.9 \\
\hline 9 & $\mathrm{E}$ & 102.4 & 0.0100 & 45 & 18.4 & 12.9 & 0.0123 & 97.4 \\
\hline 10 & $\mathrm{E}$ & 107.4 & 0.0100 & 47 & 19.2 & 13.5 & 0.0117 & 93.1 \\
\hline 11 & $\mathrm{E}$ & 107.0 & 0.0100 & 47 & 19.2 & 13.5 & 0.0126 & 100.5 \\
\hline
\end{tabular}




\begin{tabular}{ccccccccc}
12 & $\mathrm{E}$ & 103.4 & 0.0100 & 45 & 18.4 & 12.9 & 0.0119 & 95.1 \\
\hline 13 & $\mathrm{E}$ & 99.4 & 0.0100 & 43 & 17.6 & 12.3 & 0.0116 & 93.5 \\
\hline \multicolumn{2}{l}{ AVERAGE } & 105.7 & 0.0120 & 55 & 22.4 & 15.7 & 0.0136 & 92.0 \\
\hline
\end{tabular}

Table 2. Second stage results

\begin{tabular}{cccccccc}
\hline Station & $\begin{array}{c}\text { Qty of } \\
\text { Heats } \\
\text { Injected }\end{array}$ & \% Heats & $\begin{array}{c}\text { FeTi - } \\
\text { HC } \\
{[\mathbf{k g}]}\end{array}$ & $\begin{array}{c}\text { FeTi - } \\
\text { HC } \\
{[\mathbf{k g} / \text { ton] }}\end{array}$ & \% Ti & \% Yield & St. Dev. \\
\hline VD \#1 & 194 & 74.0 & 17.1 & 0.165 & 0.0102 & 88.6 & 10.0 \\
\hline VD \#2 & 56 & 21.4 & 17.8 & 0.173 & 0.0103 & 86.9 & 12.0 \\
\hline LF & 12 & 4.6 & 17.3 & 0.167 & 0.0100 & 84.1 & 8.5 \\
\hline
\end{tabular}

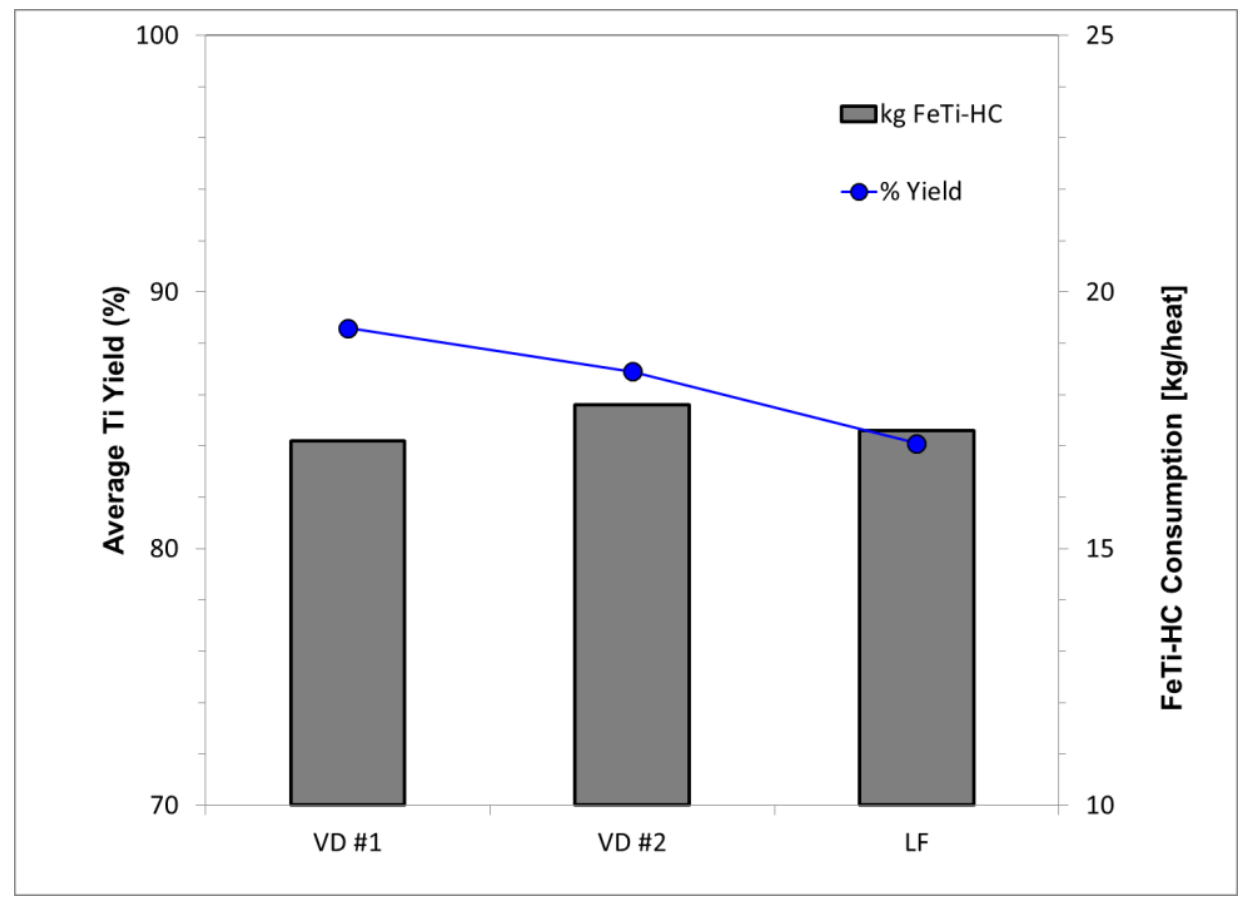

Figure 9. Ti yield \& consumption during second stage.

Figure 11 shows the variation of yield and consumption of $\mathrm{Ti}$ in the treated heats at each station (LF, VD \#1 \& VD \#2) for each different steel grade considering the two $\% \mathrm{Ti}$ target. It is observed that better yield and lower consumptions were obtained in heats with \% Ti target lower $(0.01 \%)$. For steel grades A, B \& D, only one level of \% Ti target was selected $(0.01 \%)$. For these steel grades the consumption of FeTi was optimized up to $0.160 \mathrm{~kg} / \mathrm{ton}$. Steel grades B \& D treated in VD showed very good yield results (88 \& 90\%). Such values are a consequence of the better de-oxidation obtained in VD stations. Furthermore, for A steel grade treated in the LF, its deoxidation conditions were not so favorable, thus a lower yield was achieved, i.e. $84 \%$ with the same consumption of $0.160 \mathrm{~kg} / \mathrm{ton}$. Additionally, for steel grades $\mathrm{F} \& \mathrm{G}$, a yield reduction was observed with $\% \mathrm{Ti}$ target $0.012 \%$. In order to reach such $\% \mathrm{Ti}$ objective, it was required to inject a higher quantity of $\mathrm{Ti}(0.190 \mathrm{~kg} / \mathrm{ton})$. Such heats, 
although treated in VD, showed yields in the range of $74-85 \%$, with an average of $0.0103 \% \mathrm{Ti}$. The excess of $\mathrm{Ti}$ injected may have returned to the metal-slag interphase since an important quantity of $\mathrm{FeTi} \mathrm{HC}$ reacts close to the slag resulting in its oxidation while reducing the Ti yield. Such effect is aided by an increase in the time required to melt the sheath due to its higher wall thickness.

A clear example of the increment of $\mathrm{Ti}$ yield with lower consumption is observed in steel grade $\mathrm{E}$, whose heats were treated in the VD with \%Ti target, $0.010 \%$ \& 0.012 $\%$. For this steel grade with a Ti selected was $0.012 \%$, the yields reached levels of 85 \& $80 \%$ in VD \#1 \& \#2 with a consumption of $0.019 \mathrm{~kg} /$ ton Ti. With a lower \%Ti target $(0.010 \%)$, the consumption was reduced up to $0.0160 \mathrm{~kg} / \mathrm{ton}$, having an important yield increase reaching, above $90 \%$ both VD tanks.

A summary of the average Ti yields obtained per steel grade and in each treatment station is presented in Table 3.

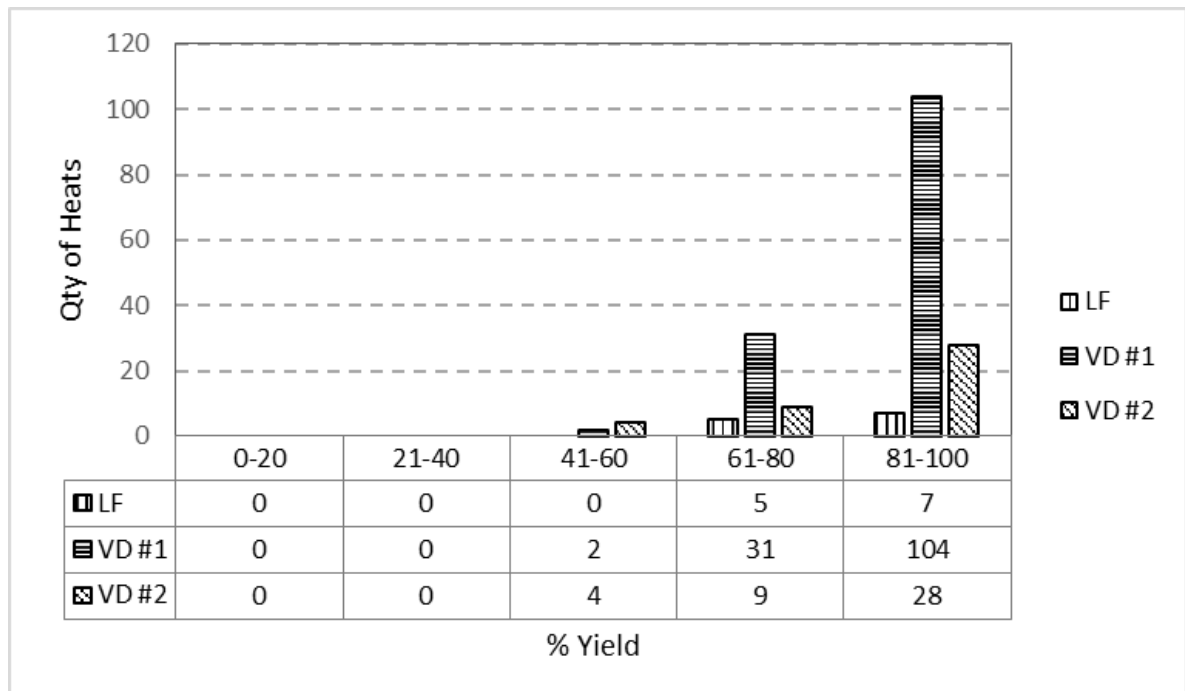

Figure 10. Ti yield \& consumption during second stage.

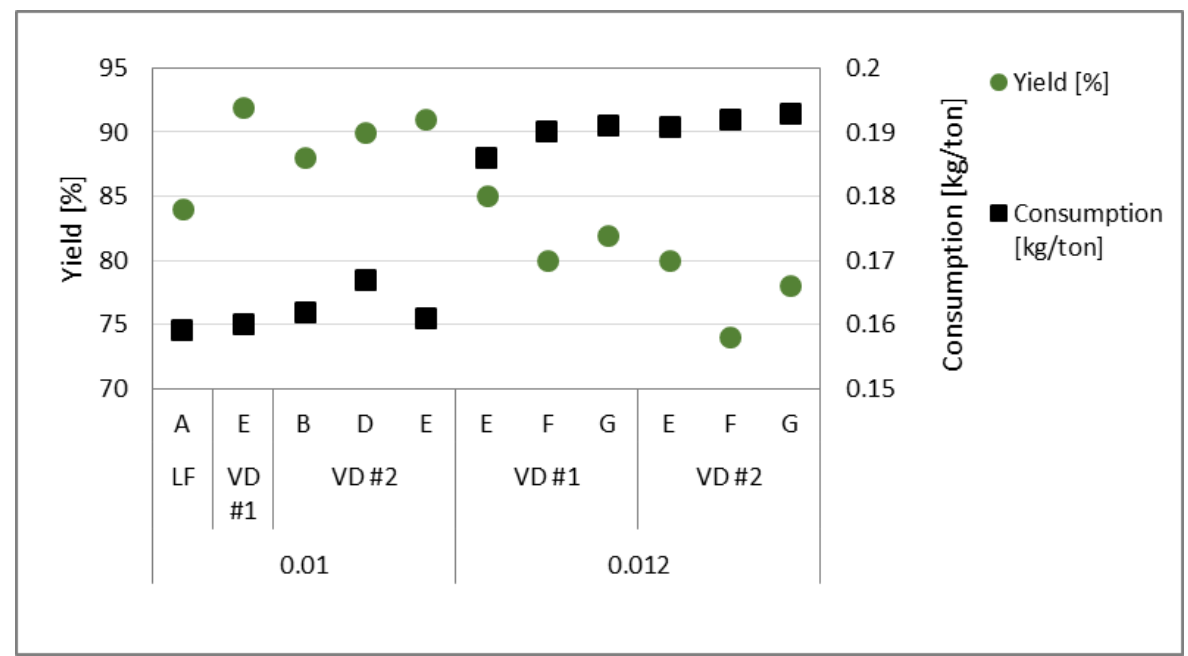

Figure 11. Ti yield \& consumption during second stage.

Table 3. Yield \& consumption results per steel grade \& station 


\begin{tabular}{cccccc}
\hline Station & Steel Grade & $\begin{array}{c}\text { FeTi - HC } \\
{[\mathbf{k g}]}\end{array}$ & $\begin{array}{c}\text { FeTi - HC } \\
{[\mathbf{k g} / \text { ton] }}\end{array}$ & \% Ti & \% Yield \\
\hline \multirow{3}{*}{ VD \#1 } & B & 15.7 & 0.159 & 0.0098 & 88.2 \\
& E & 16.8 & 0.162 & 0.0102 & 90.2 \\
& F & 19.8 & 0.190 & 0.0107 & 80.4 \\
& G & 20.7 & 0.191 & 0.0111 & 82.5 \\
\hline \multirow{2}{*}{ VD \#2 } & B & 15.8 & 0.161 & 0.0100 & 88.6 \\
& D & 17.3 & 0.167 & 0.0104 & 90.0 \\
& E & 16.9 & 0.165 & 0.0103 & 89.2 \\
\hline LF & F & 19.9 & 0.192 & 0.0100 & 74.3 \\
\hline
\end{tabular}

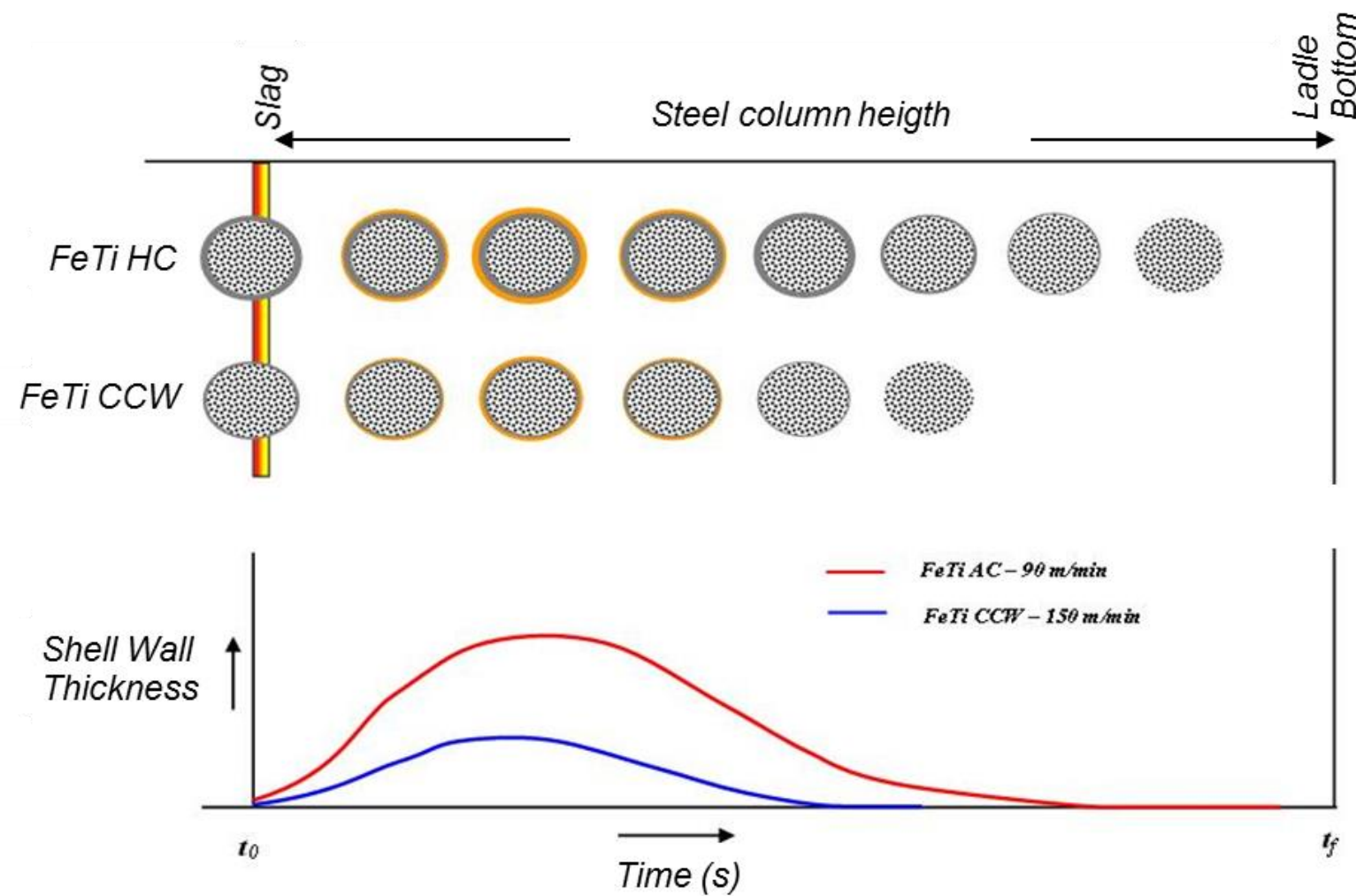

Figure 12. Diagram of solidification profile and growing of the steel shell formed around FeTi CCW and $\mathrm{FeTi} \mathrm{HC}$ injected at different speeds.

According to Sarbendu's estimations [5], for the FeTi HC wire with the largest wall thickness $(1.2 \mathrm{~mm})$, injected at a lower velocity $(90 \mathrm{~m} / \mathrm{min})$, its first "skin" of solidified steel was thicker, delaying the melting of the original wire sheath allowing to reach greater depths in the ladle. In the case of FeTi CCW, this skin layer did not have sufficient time to grow since the wire is injected at a faster rate $(120 \mathrm{~m} / \mathrm{min})$ and therefore melts earlier during injection, thus reaching lower depths in the ladle.

\section{CONCLUSIONS}


The yield of $\mathrm{Ti}$ in the Si killed high-carbon steels increased from $52 \%$ to $88 \%$, by injecting a highly compacted Ferrotitanium powder wire encapsulated in a thick sheet. The FeTi $\mathrm{HC}$ injection process was optimized by reducing the wire consumption from $0.190 \mathrm{~kg} \mathrm{FeTi}$ / ton to $0.160 \mathrm{~kg} \mathrm{FeTi} /$ ton, to obtain $0.0100 \% \mathrm{Ti}$ in the steel. The yield of Titanium with this optimization reached values between 90 and $100 \%$. The Ti yield in the steel grades A, B, D, E, F and G were evaluated. From the FeTi HC injection tests performed on the LF, it was also concluded that the deoxidation and degassing conditions of the steel affect the yield of FeTi HC, since the best yields (above 90\%) were obtained in VD \#1 \& VD \#2, where the lowest oxygen levels are achieved, while in the LF station the average yield was $84 \%$. The combination of a higher wall thickness in the wire $(1.2 \mathrm{~mm})$ and the low injection velocity $(90 \mathrm{~m} / \mathrm{min})$ enabled a better penetration of $\mathrm{FeTi} \mathrm{HC}$ in the liquid metal, maximizing Ti dissolution in steel and increasing the yield of the wire.

\section{REFERENCES}

1. Bebbington R. W. The Role of ferroboron and ferrotitanium in steels: Production Methods, Quality Aspects, and Addition Techniques. INFACON 6. Proceedings of the 1st International Chromium Steels and alloys congress. Cape Town. Volume 2 Johannesburg. SAIMM. 1992. pp. 263-267.

2. Shatokhin I.M., Bigeey V.A., Shaymardanov K.R., Manashev I.R. Investigation of combustion in Titanium-Ferrosilicon System. Vestnik of Nosov Magnitogorsk State Technical University 2013. No.5. pp 55-58.

3. Crawford G. P. Wire injection of Metallurgical powders into molten metal. INFACON 6. Proceedings of the 6th International Ferroalloys Congress. Cape Town. Volume 1 Johannesburg. SAIMM. 1992. pp. 271-277.

4. Jackisch V. J., Jackson C., Emerick J. L. Calcium Treatment of molten steel with an Innovative New Calcium Wire: Hi-Cal®.

5. Sarbendu S., Sanjay Ch., Amreekh S. and G G. Roy. Modelling Cored Wired Injection in Steels Melts. Trans. Indian Inst. Met. Vol.57, No. 2, April 2004, pp. 157-169. 